\title{
Effects of dietary glutamine and arginine supplementation on performance, intestinal morphology and ascites mortality in broiler chickens reared under cold environment
}

\author{
Rahim Abdulkarimi ${ }^{1, *}$, Mohammad Hossein Shahir ${ }^{1}$, and Mohsen Daneshyar ${ }^{2}$
}

* Corresponding Author: Rahim Abdulkarimi Tel: +98-9141801681, Fax: +98-4446223534, E-mail: Rahim.abdulkarimi@yahoo.com

'Department of Animal Science, Faculty of Agriculture, University of Zanjan, Zanjan 45371-38791, Iran

2 Department of Animal Science, Faculty of Agriculture, Urmia University, Urmia 57561-51818, Iran

ORCID

Rahim Abdulkarimi

https://orcid.org/0000-0003-1921-5493

Mohammad Hossein Shahir

https://orcid.org/0000-0003-2327-1877

Mohsen Daneshyar

https://orcid.org/0000-0003-1854-210X

Submitted Feb 28, 2017; Revised Apr 7, 2017; Accepted May 24, 2017
Objective: An experiment was conducted to evaluate the effects of dietary glutamine (Gln) and arginine (Arg) supplementation on performance, intestinal morphology and ascites mortality in broilers.

Methods: A total of 675 day old chicks were randomly allocated to 9 experimental groups in a $3 \times 3$ factorial arrangement based on a completely randomized design with 5 replicates of 15 chicks. Three levels of dietary Gln (0\%, $0.5 \%$, and $1 \%)$ and $\operatorname{Arg}(100 \%, 130 \%$, and $160 \%$ of Ross recommendation) supplementation were used in ascites inducing condition $\left(15^{\circ} \mathrm{C}\right.$ $\pm 1^{\circ} \mathrm{C}$ ) from 7 to 42 days of age.

Results: Dietary supplementation of Gln increased body weight gain during grower, finisher and total periods $(\mathrm{p}<0.05)$ and increased feed intake during total period. Ascites mortality was decreased by Gln supplementation $(\mathrm{p}<0.05)$. Gln supplementation increased the villus height $(\mathrm{VH})$ and crypt depth $(\mathrm{CD})$ in duodenum and jejunum $(\mathrm{p}<0.05)$. Arg supplementation decreased $C D$ in duodenum and jejunum, and increased ileum villus width (VW) and also $\mathrm{VH} / \mathrm{CD}$ ratio in duodenum and jejunum $(\mathrm{p}<0.05)$. Both Gln and Arg increased the goblet cell number (GCN) in duodenum whereas Gln supplementation decreased GCN in jejunum and ileum $(\mathrm{p}<0.05)$. The Gln $\times$ Arg interaction were observed for right ventricle $(\mathrm{RV}) /$ total ventricular (TV) ratio, $\mathrm{VH}, \mathrm{VW}, \mathrm{CD}, \mathrm{VH} / \mathrm{CD}$.

Conclusion: It was concluded that dietary $0.5 \%$ Gln alone or along with 130\% Arg of Ross requirement, improve the intestinal morphology and performance and hence decrease the ascites mortality in broiler chickens with cold induced ascites.

Keywords: Ascites; Arginine; Broiler Chickens; Glutamine; Intestinal Morphology

\section{INTRODUCTION}

Ascites or pulmonary hypertension syndrome (PHS) is one of the main causes of mortality in modern broilers. It is estimated that ascites incidence may be as high as $20 \%$ of total mortality in broilers [1]. Due to selection for rapid growth, broiler chickens have a high metabolic rate and hence higher oxygen requirements. However, they have a marginal capacity of lung and cardiovascular systems to supply their high oxygen demand. This results in impaired ability to regulate the blood oxygen under extreme conditions such as low ambient temperature or high altitude and leads to hypoxemia, increased cardiac output, pulmonary hypertension, right ventricular hypertrophy and finally ascites and death [2]. Among the organs of broilers, gastrointestinal tract (GIT) is a highly metabolic active organ that demands high oxygen supply. The total oxygen demand of gut is not known for broilers, but in pigs it consumes about $25 \%$ of the total oxygen, while it represents only $5 \%$ of total body weight [3]. The negative effects of heat stress, oxidative stress and hypoxic conditions has been well documented 
on gastrointestinal function and metabolism of monogastric animals $[4,5]$. Therefore it can be postulated that improvement of gut integrity and function can have beneficial effects on broiler health and performance in ascites inducing conditions.

Recent studies have shown that supplementation of certain amino acids can promote gut function, gastrointestinal integrity and subsequently growth performance of broilers [6]. Glutamine (Gln) and arginine (Arg) stimulate gut development and improve the overall efficiency of the chicken GIT $[7,8]$. The benefits of dietary Gln supplementation on performance, gut morphology and immune responses have recently been reported in poultry [7,9-11]. Although Gln is a non-essential amino acid, it is considered as an essential amino acid under challenging conditions [12]. Gln is the main energy source for rapidly proliferating cells such as intestinal enterocytes [13] and plays an important role in the intestinal immune system, mucin synthesis, maintenance of mucosal structure and integrity of epithelial barrier against pathogen attacks $[11,14]$.

Arg is an essential amino acid for birds which cannot be synthesized by de novo routes, and birds are dependent on dietary supply [15]. Arg has been recognized as one of the functional amino acids that regulates key metabolic pathways and necessary for maintenance, growth, reproduction, and immunity [15]. Arg contributes in the synthesis of several crucial compounds such as nitric oxide (NO), creatine, polyamines, citrulline, ornithine, proline, glutamate, and enhances secretion of insulin, growth hormone and insulin-like growth factor 1 in animals $[15,16]$. Arg involvement in polyamines synthesis plays an important role in development of small intestinal mucosa and growth [17]. Arg supplementation, has improved the production performance and intestinal morphology of broilers [15]. Supplementation of $10 \mathrm{~g} / \mathrm{kg}$ Arg, has reduced the susceptibility to PHS and improved gut function through increase in villus height $(\mathrm{VH})$ of small intestine in broilers reared at high altitude [8].

The beneficial effects of Gln and Arg supplementation on production performance and gut function has been accepted under normal rearing conditions. However, not enough information is available regarding the effects of dietary supplementation by Gln and Arg, alone or in combination, under ascites inducing cold ambient conditions. Therefore, current study was conducted to assess the effects of different levels of these two amino acids on performance, intestinal morphology and ascites incidence in broilers reared under cold environment.

\section{MATERIAL AND METHODS}

All of the experimental protocols were reviewed and approved by the animal care and use committee of the University of Zanjan, Iran. A total of 675 day old female chicks (Ross 308, $45 \pm 3 \mathrm{~g}$ ) were obtained from a commercial hatchery and reared in an environmentally controlled house at the altitude of 1,670 meters under ascites inducing cold condition after 7 days until 42 days of age. At the beginning of experiment, birds were randomly allocated to 9 treatments with 5 replicate pens and 15 chicks for each based on a completely randomized design in a $3 \times 3$ factorial arrangement (glutaminexarginine levels). Three levels of dietary Gln (0\%, $0.5 \%$, and $1 \%)$, and $\operatorname{Arg}(100 \%$, $130 \%$, and $160 \%$ of Ross 308 recommendation) supplementation were used. A basal diet was formulated with cornsoybean meal according to Ross (308) recommendation (Table 1) and supplementation of Gln and Arg was performed on top of the basal diet. The L-Arg hydrochloride (99.6\% purity) and L-Gln (98.7\% purity) were purchased from Vitajoy company, China (B13-102, NO.192, Tinglan Lane, Suzhou, Jiangsu, China). Water and feed were provided ad libitum and birds were subjected to $23 \mathrm{~h}$ light and $1 \mathrm{~h}$ dark throughout the

Table 1. Ingredient and chemical composition of basal diets

\begin{tabular}{|c|c|c|c|}
\hline Items & $\begin{array}{l}\text { Starter } \\
(1-10 \mathrm{~d})\end{array}$ & $\begin{array}{l}\text { Grower } \\
(11-24 d)\end{array}$ & $\begin{array}{l}\text { Finisher } \\
(25-42 d)\end{array}$ \\
\hline \multicolumn{4}{|l|}{ Ingredients (\%) } \\
\hline Corn $(7.34 \%)$ & 44.029 & 52.05 & 58.445 \\
\hline Corn gluten meal (52.19\%) & 9.409 & 0.0 & 0.0 \\
\hline Soybean meal (45.45\%) & 39.369 & 40.078 & 34.319 \\
\hline Soy oil & 2.392 & 3.815 & 3.397 \\
\hline Dicalcium phosphate & 2.223 & 1.956 & 1.811 \\
\hline Calcium carbonate & 1.219 & 0.969 & 0.955 \\
\hline L-lysine $\mathrm{HCl}(78 \%)$ & 0.242 & 0.029 & 0.02 \\
\hline DL-methionine (99\%) & 0.214 & 0.245 & 0.207 \\
\hline Vitamin and mineral premix ${ }^{1)}$ & 0.5 & 0.5 & 0.5 \\
\hline Salt & 0.255 & 0.326 & 0.326 \\
\hline Sodium bicarbonate & 0.149 & 0.031 & 0.02 \\
\hline Total & 100 & 100 & 100 \\
\hline \multicolumn{4}{|l|}{ Calculated analysis } \\
\hline Dry matter (\%) & 89.801 & 89.535 & 89.17 \\
\hline $\begin{array}{l}\text { Metabolizable energy (kcal/ } \\
\mathrm{kg} \text { ) }\end{array}$ & 2,950 & 3,000 & 3,050 \\
\hline Ether extract (\%) & 4.294 & 5.799 & 5.581 \\
\hline Calcium (\%) & 1.027 & 0.88 & 0.831 \\
\hline Available phosphorus (\%) & 0.491 & 0.44 & 0.411 \\
\hline Chloride (\%) & 0.23 & 0.23 & 0.23 \\
\hline Sodium (\%) & 0.167 & 0.162 & 0.158 \\
\hline Methionine $(\%)^{2)}$ & $0.643(0.613)$ & $0.569(0.543)$ & $0.506(0.481)$ \\
\hline Lysine (\%) & $1.478(1.34)$ & $1.256(1.12)$ & $1.104(0.984)$ \\
\hline Arginine (\%) & $1.632(1.50)$ & $1.512(1.38)$ & $1.347(1.13)$ \\
\hline Methionine+cystine (\%) & $1.083(0.987)$ & $0.924(0.841)$ & $0.835(0.759)$ \\
\hline Threonine (\%) & $1.004(0.895)$ & $0.856(0.755)$ & $0.771(0.678)$ \\
\hline Tryptophan (\%) & $0.298(0.254)$ & $0.278(0.237)$ & $0.246(0.210)$ \\
\hline
\end{tabular}

1) Supplied per kilogram of diet: retinol, 9,000 IU; alpha tochopherol acetate, $36 \mathrm{IU}$; cholecaciferol, 2,000 IU; cyanocobalamin, $0.015 \mathrm{mg}$; riboflavin, 6.6 $\mathrm{mg}$; calcium pantothenate, $9.8 \mathrm{mg}$; niacin, $30 \mathrm{mg}$; choline chloride, $625 \mathrm{mg}$; biotin, $0.1 \mathrm{mg}$; thiamine, $1.75 \mathrm{mg}$; pyridoxine, $3 \mathrm{mg}$; folic acid, $1 \mathrm{mg}$; menadione, 2 mg; antioxidant (ethoxy queen), 100 mg; manganese, 248 mg; zinc, $211 \mathrm{mg}$; copper, $25 \mathrm{mg}$; iron, $125 \mathrm{mg}$; iodine, $2.5 \mathrm{mg}$; selenium, $0.5 \mathrm{mg}$.

${ }^{2)}$ Amino acid values represent both the total amino acid value and standardised ileal digestibility (SID) of amino acid value (in parentheses). 
experimental period. The birds were raised under standard conditions during the first week of age, but in order to induce ascites, temperature was reduced to $26.0^{\circ} \mathrm{C} \pm 1^{\circ} \mathrm{C}, 20.0^{\circ} \mathrm{C} \pm 1^{\circ} \mathrm{C}$, and $15.0^{\circ} \mathrm{C} \pm 1^{\circ} \mathrm{C}$ at 7,14 , and $21 \mathrm{~d}$ of age respectively and maintained at $15.0^{\circ} \mathrm{C} \pm 1^{\circ} \mathrm{C}$ until the end of the experiment [2]. The average feed intake (FI, g/bird/d), body weight gain (BWG, $\mathrm{g} / \mathrm{bird} / \mathrm{d}$ ) and feed conversion ratio (FCR) were determined during the starter ( 1 to $10 \mathrm{~d}$ ), grower (11 to $24 \mathrm{~d}$ ), finisher (25 to $42 \mathrm{~d}$ ), and whole ( 1 to $42 \mathrm{~d}$ ) periods.

During the experiment, mortality was recorded daily and all of the dead chickens were necropsied for ascites diagnosis based on amber colored fluid accumulation in abdominal cavity and pericardium, vascular congestion and ratio of right to total ventricular (TV) weight more than 0.29 [18]. The dead birds without the above mentioned symptoms were categorized as non-ascites mortality. Daily ascites mortality was recorded for each pen separately and at the end of the experimental period ascites mortality percentage calculated by number of dead birds due to ascites/total birds in each pen [19]. At 42 days of age, two birds per pen were selected, weighed and killed by decapitation to obtain the visceral organs weight (liver, gizzard, pancreas, and spleen), heart and intestinal segments. The liver, gizzard, pancreas and spleen removed, weighted and proportional weights of each organ were calculated relative to live weight. The heart was dissected and proportional weight of TV and right ventricle (RV) was determined RV to TV ratio was calculated. The small intestine was removed (from gizzard to ileocecal junction) and emptied of digesta contents. Then, the length and weight of whole intestine were measured. For experimental samples, small intestine divided into 3 segments and two $\mathrm{cm}$ of the middle portions of duodenum (from gizzard to entry of the bile and pancreatic ducts), jejunum (from entry of the ducts to diverticulum vitellinum), and ileum (from diverticulum vitellinum to the ileocecal junction) were cut, digesta was carefully washed away using normal saline, and samples were placed in $10 \%$ buffered formalin. Samples were dehydrated by alcohol, infiltrated with xylene and then embedded in paraffin. The paraffin sections were cut in $7.00 \mu \mathrm{m}$ size by microtome and then stained by hematoxylin and eosin for $\mathrm{VH}$, villus width (VW), and crypt depth (CD) measurement. The goblet cells numbers (GCN) were identified by periodic acid-schiff stain [20]. At the end, these samples were examined by multiple magnification (optical lens $400 \times$ and $1,000 \times$ ) and morphometric analysis of digital photos of light microscopy were performed by means of image J analysis software [20]. The VH was measured from the top of the villus to the top of the lamina propria. The VW was averaged from VW at one-third and two-third of each villus. The $\mathrm{CD}$ was measured as the distance between the base of the villus to the sub mucosa [8]. After measuring of $\mathrm{VH}$ and $\mathrm{CD}$, the $\mathrm{VH}$ to $\mathrm{CD}$ ratio $(\mathrm{VH} / \mathrm{CD})$ was calculated separately for each part. All procedures including the uses of birds, management and care were in compliance with the European parliament and the European Council Directive regulations on the protection of animals used for scientific purposes (2010/63/EU).

The data were analyzed by the general linear model procedure of SAS (SAS Institute, 2003, Version 9.1.2) and difference between treatments means were evaluated by Tukey's test at a significance level of $5 \%$. The following model was used:

$$
Y_{\mathrm{ijkl}}=\mu+A_{i}+G_{j}+A G_{i j}+e_{i j k l}
$$

In which $A_{i}\left(\right.$ Arg level) and $G_{j}$ (Glu level) were considered as the main effects and $A G_{i j}$ as the interaction.

\section{RESULTS}

\section{Performance and ascites mortality}

The effects of dietary Arg and Gln supplementation on performance, ascites mortality and RV/TV are presented in Table 2 and 3 . There were no significant differences between treatments in FI during the experimental periods but the main effect of Gln supplementation was significant during the total period $(\mathrm{p}<0.05)$ and the birds fed the medium level of $\mathrm{Gln}$ $(0.5 \%)$ had higher FI. Dietary supplementation of $0.5 \%$ Gln had significant effect on BWG during the grower, finisher and total periods ( $\mathrm{p}<0.05$ ). The birds fed $0.5 \% \mathrm{Gln}+160 \% \mathrm{Arg}$ in diet had the highest BWG during grower, finisher and total periods $(\mathrm{p}<0.05)$. No interactions were found between the $\mathrm{Gln}$ and Arg on FI, BWG, and FCR. Supplementation of $0.5 \%$ Gln significantly reduced the FCR during finisher period $(\mathrm{p}<0.05)$. The experimental protocol was successful in ascites induction (ascites mortality of $46.6 \%$ in the control group). Ascites mortality reduced by $0.5 \%$ Gln supplementation $(\mathrm{p}<0.05)$ but not by Arg supplementation. The lowest ascites mortality (14.67\%) attributed to $0.5 \% \mathrm{Gln}+130 \% \operatorname{Arg}$ experimental group $(\mathrm{p}<0.05)$.

\section{Small intestinal segments and visceral organs}

The effects of dietary Gln and Arg supplementation on small intestinal length, small intestinal weight and visceral organs weight are summarized in Table 4. Dietary Arg and Gln supplementation had no significant effects on the length and proportional weight of small intestine and on the visceral organs proportional weights. Furthermore, there was no significant interaction between Arg and Gln levels for the above mentioned parameters.

\section{Small intestinal morphology}

Effects of dietary Gln and Arg supplementation on the morphology of small intestinal segments are presented in Table 5. Dietary Gln affected the VH in duodenum and jejunum ( $\mathrm{p}<$ 0.05). The birds fed the $0.5 \%$ Gln along with $130 \%$ Arg had the highest $\mathrm{VH}$ as compared to the birds in other treatments. 
Table 2. The effects of dietary supplementation with glutamine $(\mathrm{Gln})$ and arginine (Arg) on feed intake ( $\mathrm{g} / \mathrm{b}$ ird/d), weight gain ( $\mathrm{g} / \mathrm{bird} / \mathrm{d})$, FCR, and mortality ratio in broiler reared under cold environmental temperature (7 to 42 days of age)

\begin{tabular}{|c|c|c|c|c|c|c|c|c|c|c|c|c|c|}
\hline \multirow{2}{*}{ Arginine } & \multicolumn{3}{|c|}{ Glutamine $(0 \%)$} & \multicolumn{3}{|c|}{ Glutamine $(0.5 \%)$} & \multicolumn{3}{|c|}{ Glutamine (1\%) } & \multirow{2}{*}{ SEM } & \multicolumn{3}{|c|}{$p$ value } \\
\hline & $100 \%$ & $130 \%$ & $160 \%$ & $100 \%$ & $130 \%$ & $160 \%$ & $100 \%$ & $130 \%$ & $160 \%$ & & Gln & Arg & $\mathrm{Gln} \times \mathrm{Arg}$ \\
\hline \multicolumn{14}{|l|}{ Feed intake } \\
\hline Grower & 69.84 & 60.49 & 68.51 & 70.81 & 71.00 & 69.62 & 65.05 & 67.74 & 66.95 & 2.47 & 0.08 & 0.50 & 0.12 \\
\hline Finisher & 140.10 & 145.30 & 144.40 & 150.00 & 163.30 & 165.10 & 143.30 & 135.80 & 136.60 & 10.75 & 0.056 & 0.87 & 0.85 \\
\hline Total & 77.98 & 76.60 & 78.70 & 81.54 & 85.96 & 86.18 & 77.49 & 75.90 & 75.86 & 3.93 & 0.034 & 0.92 & 0.91 \\
\hline Starter & 15.96 & 15.90 & 15.42 & 15.60 & 15.97 & 16.05 & 15.99 & 16.48 & 16.16 & 0.44 & 0.45 & 0.73 & 0.83 \\
\hline Grower & $31.16^{\mathrm{ab}}$ & $28.47^{b}$ & $31.00^{\mathrm{ab}}$ & $33.01^{\mathrm{ab}}$ & $34.18^{\mathrm{ab}}$ & $36.62^{\mathrm{a}}$ & $29.92^{\mathrm{ab}}$ & $31.34^{\mathrm{ab}}$ & $29.58^{\mathrm{ab}}$ & 1.57 & 0.001 & 0.64 & 0.37 \\
\hline Finisher & $52.99^{b}$ & $62.52^{\mathrm{ab}}$ & $65.30^{\mathrm{ab}}$ & $68.57^{\mathrm{ab}}$ & $72.39^{\mathrm{ab}}$ & $75.37^{\mathrm{a}}$ & $63.62^{\mathrm{ab}}$ & $60.93^{\mathrm{ab}}$ & $64.43^{\mathrm{ab}}$ & 4.3 & 0.004 & 0.18 & 0.64 \\
\hline Total & $33.36^{c}$ & $35.63^{b c}$ & $37.24^{b c}$ & $39.06^{\mathrm{ab}}$ & $40.84^{\mathrm{ab}}$ & $42.68^{\mathrm{a}}$ & $36.51^{\mathrm{bc}}$ & $36.25^{b c}$ & $36.71^{b c}$ & 1.66 & 0.0007 & 0.18 & 0.81 \\
\hline \multicolumn{14}{|l|}{ FCR } \\
\hline Starter & 1.50 & 1.51 & 1.50 & 1.50 & 1.46 & 1.48 & 1.49 & 1.46 & 1.48 & 0.03 & 0.53 & 0.70 & 0.92 \\
\hline Ascites mortality (\%) & $46.60^{\mathrm{a}}$ & $26.67^{\mathrm{ab}}$ & $37.33^{\mathrm{ab}}$ & $17.33^{\mathrm{ab}}$ & $14.67^{b}$ & $22.67^{\mathrm{ab}}$ & $18.67^{\mathrm{ab}}$ & $32.00^{\mathrm{ab}}$ & $17.33^{\mathrm{ab}}$ & 7.63 & 0.003 & 0.85 & 0.12 \\
\hline RV/TV ratio & $0.27 .3^{\mathrm{a}}$ & $0.15^{b}$ & $0.22^{\mathrm{ab}}$ & $0.22^{\mathrm{ab}}$ & $0.25^{\mathrm{ab}}$ & $0.25^{\mathrm{ab}}$ & $0.22^{\mathrm{ab}}$ & $0.23^{\mathrm{ab}}$ & $0.25^{\mathrm{ab}}$ & 0.022 & 0.39 & 0.32 & 0.016 \\
\hline
\end{tabular}

SEM, standard error of the mean; FCR, feed conversion ratio; RV, right ventricle; TV, total ventricular.

1) Starter (1-10d), grower (11-24d), finisher (25-42d), total (1-42 d).

$a, b$ Means in each row with no common superscript differ significantly $(p<0.05)$.

Increasing the Gln level to $0.5 \%$ increased the $\mathrm{VH}$ only at the $130 \%$ Arg level whereas this increase was not observed at the other levels of Arg (Gln $\times$ Arg interaction). The $\mathrm{VH}$ of ileum was not affected by Gln or Arg supplementation. No effects of Arg and Gln or their interaction were found on VW in the duodenum and jejunum. VW of ileum increased by $\operatorname{Arg}(\mathrm{p}<$ 0.05 ) and this effect was observed only at $0.0 \%$ and $0.5 \%$ of Gln (Gln $\times$ Arg interaction). Gln supplementation changed the

Table 3. The main effects of dietary supplementation with glutamine (GIn) and arginine (Arg) on feed intake (g/bird/d), weight gain (g/bird/d), FCR, mortality and RV/TV ratio in broiler reared under cold environmental temperature ( 7 to 42 days of age)

\begin{tabular}{|c|c|c|c|c|c|c|c|c|c|c|}
\hline \multirow{2}{*}{ Items } & \multicolumn{3}{|c|}{ Glutamine levels } & \multirow{2}{*}{ SEM } & \multirow{2}{*}{$p$ value } & \multicolumn{3}{|c|}{ Arginine levels } & \multirow{2}{*}{ SEM } & \multirow{2}{*}{$p$ value } \\
\hline & $(0 \%)$ & $(0.5 \%)$ & $(1 \%)$ & & & $100 \%$ & $130 \%$ & $160 \%$ & & \\
\hline \multicolumn{11}{|l|}{ Feed intake } \\
\hline Starter ${ }^{1)}$ & 23.782 & 23.69 & 24.09 & 0.387 & 0.64 & 23.94 & 23.94 & 23.67 & 0.39 & 0.78 \\
\hline Grower & 66.28 & 70.48 & 66.58 & 1.43 & 0.08 & 68.57 & 66.41 & 68.36 & 1.43 & 0.50 \\
\hline Finisher & 143.3 & 159.52 & 138.59 & 6.21 & 0.055 & 144.5 & 148.17 & 148.73 & 6.21 & 0.87 \\
\hline Total & $77.79^{b}$ & $84.56^{\mathrm{a}}$ & $76.42^{b}$ & 2.27 & 0.034 & 79 & 79.51 & 80.25 & 2.27 & 0.92 \\
\hline \multicolumn{11}{|l|}{ Weight gain } \\
\hline Starter & 15.76 & 15.87 & 16.21 & 0.25 & 0.45 & 15.85 & 16.12 & 15.88 & 0.25 & 0.73 \\
\hline Grower & $30.21^{\mathrm{b}}$ & $34.61^{\mathrm{a}}$ & $30.28^{b}$ & 0.909 & 0.001 & 31.36 & 31.33 & 32.4 & 0.91 & 0.64 \\
\hline Finisher & $60.27^{b}$ & $72.11^{\mathrm{a}}$ & $62.99^{b}$ & 2.48 & 0.004 & 61.72 & 65.28 & 68.36 & 2.48 & 0.18 \\
\hline Total & $35.41^{\mathrm{b}}$ & $40.86^{a}$ & $36.49^{b}$ & 0.96 & 0.0007 & 36.31 & 37.58 & 38.88 & 0.96 & 0.18 \\
\hline \multicolumn{11}{|l|}{ FCR } \\
\hline Starter & 1.5 & 1.48 & 1.48 & 0.017 & 0.53 & 1.5 & 1.48 & 1.49 & 0.02 & 0.70 \\
\hline Grower & 2.21 & 2.14 & 2.2 & 0.056 & 0.61 & 2.23 & 2.17 & 2.15 & 0.056 & 0.66 \\
\hline Finisher & $2.41^{a}$ & $2.2^{b}$ & $2.19^{b}$ & 0.062 & 0.031 & 2.36 & 2.25 & 2.19 & 0.06 & 0.16 \\
\hline Total & 2.2 & 2.07 & 2.09 & 0.041 & 0.06 & 2.18 & 2.11 & 2.07 & 0.04 & 0.20 \\
\hline Ascites mortality (\%) & $36.88^{\mathrm{a}}$ & $18.22^{b}$ & $22.66^{\mathrm{ab}}$ & 3.88 & 0.003 & 27.55 & 24.44 & 25.77 & 3.88 & 0.85 \\
\hline $\mathrm{RV} / \mathrm{TV}$ & 0.21 & 0.24 & 0.23 & 0.013 & 0.39 & 0.24 & 0.21 & 0.24 & 0.01 & 0.32 \\
\hline
\end{tabular}

SEM, standard error of the mean; FCR, feed conversion ratio; RV, right ventricle; TV, total ventricular.

1) Starter (1-10d), grower (11-24d), finisher (25-42d), total (1-42d).

$a, b$ Means in each row with no common superscript differ significantly $(p<0.05)$. 
Table 4. The effects of dietary supplementation with Glutamine (Gln) and Arginine (Arg) on length, proportional weight of small intestine, and proportional weight of visceral organs in broiler reared under cold environmental condition

\begin{tabular}{|c|c|c|c|c|c|c|c|c|c|c|c|c|c|}
\hline \multirow{2}{*}{ Arginine } & \multicolumn{3}{|c|}{ Glutamine $(0 \%)$} & \multicolumn{3}{|c|}{ Glutamine $(0.5 \%)$} & \multicolumn{3}{|c|}{ Glutamine (1\%) } & \multirow{2}{*}{ SEM } & \multicolumn{3}{|c|}{$p$ value } \\
\hline & $100 \%$ & $130 \%$ & $160 \%$ & $100 \%$ & $130 \%$ & $160 \%$ & $100 \%$ & $130 \%$ & $160 \%$ & & $\mathrm{Gln}$ & Arg & Gln $\times$ Arg \\
\hline Small intestinal length $(\mathrm{cm})$ & 152.8 & 152.8 & 149.6 & 156.2 & 164.6 & 144.2 & 159 & 152 & 164 & 6.6 & 0.5 & 0.74 & 0.24 \\
\hline Small intestinal weight ${ }^{1)}$ & 3.5 & 3.03 & 2.5 & 3.44 & 3.14 & 3.33 & 2.81 & 3.25 & $3 . .21$ & 0.41 & 0.67 & 0.78 & 0.52 \\
\hline \multicolumn{14}{|l|}{ Organs weight"1) } \\
\hline Liver & 3.47 & 2.69 & 2.82 & 2.64 & 3.04 & 2.2 & 2.5 & 3.17 & 2.62 & 0.29 & 0.31 & 0.20 & 0.13 \\
\hline Gizzard & 1.94 & 1.72 & 1.75 & 1.84 & 1.74 & 1.79 & 1.74 & 1.85 & 1.47 & 0.15 & 0.63 & 0.45 & 0.66 \\
\hline Pancreas & 0.26 & 0.22 & 0.61 & 0.25 & 0.24 & 0.21 & 0.57 & 0.29 & 0.21 & 0.17 & 0.59 & 0.72 & 0.36 \\
\hline Spleen & 0.2 & 0.14 & 0.12 & 0.18 & 0.12 & 0.13 & 0.13 & 0.14 & 0.12 & 0.021 & 0.45 & 0.06 & 0.38 \\
\hline
\end{tabular}

SEM, standard error of the mean.

1) Proportional weight $=$ weight segment or organ/final live body weight.

$\mathrm{CD}$ in duodenum and jejunum ( $\mathrm{p}<0.05)$. The $0.5 \% \mathrm{Gln}+130 \%$ Arg fed birds had the highest $\mathrm{CD}$ in both the duodenum and jejunum (Gln $\times$ Arg interaction, $p<0.05)$. No effects of Arg and Gln or their interaction was detected for CD in ileum. The $\mathrm{VH} / \mathrm{CD}$ ratio was increased by Arg supplementation in duodenum and jejunum $(\mathrm{p}<0.05)$. At the medium Gln level $(0.5 \%)$, increasing the Arg level to $160 \%$ increased the $\mathrm{VH} / \mathrm{CD}$ ratio (Gln $\times$ Arg interaction, $\mathrm{p}<0.05$ ). No effect of Arg, Gln and their interaction was observed on $\mathrm{VH} / \mathrm{CD}$ ratio in ileum. Both the Gln and Arg affected the goblet cell number (GCN) in duodenum ( $\mathrm{p}<0.05$ ) and the $0.5 \% \mathrm{Gln}+130 \%$ Arg and $1.0 \% \mathrm{Gln}+$ $160 \%$ Arg fed birds had higher GCN. Only Gln affected the GCN in the jejunum and ileum $(\mathrm{p}<0.05)$. No interaction be- tween Arg and Gln was observed for GCN in all intestine parts $(\mathrm{p}>0.05)$.

\section{DISCUSSION}

The beneficial effects of Gln supplementation on BWG and intestinal morphology in the recent experiment have been shown. This results supported by Bartell and Batal [11] and Soltan [9], who observed that consumption of $1.0 \%$ Gln in broilers, resulted in longer villi height and higher relative weights of duodenum and jejunum, and consequently higher BWG. In stressful conditions with high ambient temperature, Jazideh et al [7] reported that dietary supplementation of $0.5 \%$

Table 5. The effects of dietary supplementation with glutamine (GIn) and arginine (Arg) on villus height, villus width, crypt depth, villus height/crypt depth ratio and goblet cell number (GCN) in small intestine of broiler reared under cold environmental condition

\begin{tabular}{|c|c|c|c|c|c|c|c|c|c|c|c|c|c|}
\hline \multirow{2}{*}{ Arginine } & \multicolumn{3}{|c|}{ Glutamine $(0 \%)$} & \multicolumn{3}{|c|}{ Glutamine $(0.5 \%)$} & \multicolumn{3}{|c|}{ Glutamine $(1 \%)$} & \multirow{2}{*}{ SEM } & \multicolumn{3}{|c|}{$p$ value } \\
\hline & $100 \%$ & $130 \%$ & $160 \%$ & $100 \%$ & $130 \%$ & $160 \%$ & $100 \%$ & $130 \%$ & $160 \%$ & & Gln & Arg & Gln $\times$ Arg \\
\hline \multicolumn{14}{|c|}{ Villus height ( $\mu \mathrm{m})$} \\
\hline Duodenum & $1,530.30^{d}$ & $1,564.60^{d}$ & $1,710^{\mathrm{ab}}$ & $1,665.30^{\mathrm{bc}}$ & $1,782.60^{\mathrm{a}}$ & $1,510^{d}$ & $1,585.60^{\text {cd }}$ & $1,501^{d}$ & $1,659 \cdot 60^{\mathrm{bc}}$ & 18.7 & 0.0007 & 0.12 & 0.0001 \\
\hline Jejunum & $1,220.60^{d}$ & $1,247.00^{d}$ & $1,298.60^{c}$ & $1,366.30^{b}$ & $1,420.30^{\mathrm{a}}$ & $1,230^{\mathrm{d}}$ & $1,269.30^{\text {cd }}$ & $1,224^{d}$ & $1,297.30^{c}$ & 15.8 & 0.0001 & 0.26 & 0.0001 \\
\hline lleum & 852.60 & 884.00 & 867.30 & 859.30 & 907.60 & 871.60 & 872.60 & 881.60 & 885.00 & 20.4 & 0.72 & 0.23 & 0.86 \\
\hline \multicolumn{14}{|l|}{ Villus with $(\mu \mathrm{m})$} \\
\hline Duodenum & 125.60 & 128.60 & 121.00 & 124.60 & 115.30 & 127.30 & 129.60 & 130.30 & 125.00 & 3.46 & 0.14 & 0.70 & 0.08 \\
\hline Jejunum & 127.00 & 122.30 & 131.30 & 117.00 & 118.60 & 130.60 & 121.60 & 125.60 & 123.30 & 3.48 & 0.48 & 0.14 & 0.41 \\
\hline lleum & $136.00^{\mathrm{abc}}$ & $128.00 c$ & $154.60^{\mathrm{a}}$ & $125.30^{c}$ & $135.30^{\mathrm{bc}}$ & $151.00^{\mathrm{ab}}$ & $134.60^{\mathrm{bc}}$ & $131.30 c$ & $132.30^{\mathrm{bc}}$ & 3.81 & 0.11 & 0.0002 & 0.005 \\
\hline \multicolumn{14}{|l|}{ Crypt deth $(\mu \mathrm{m})$} \\
\hline Duodenum & $121.60^{\mathrm{bc}}$ & $120.30^{\text {bc }}$ & $121.60^{\mathrm{bc}}$ & $135.6^{\mathrm{ab}}$ & $147.30^{\mathrm{a}}$ & $103.00^{d}$ & $122.00^{\mathrm{bc}}$ & $107.00^{\text {cd }}$ & $123.00^{b c}$ & 3.46 & 0.002 & 0.003 & 0.0001 \\
\hline Jejunum & $124.60^{\mathrm{bc}}$ & $121.60^{b c d}$ & $117.00^{\text {cde }}$ & $137.00^{\mathrm{ab}}$ & $142.60^{\mathrm{a}}$ & $102.60^{e}$ & $127.30^{\mathrm{abc}}$ & $104.00^{\text {de }}$ & $127.60^{\mathrm{abc}}$ & 20.46 & 0.037 & 0.0006 & 0.0001 \\
\hline lleum & 93.66 & 88.00 & 84.33 & 89.00 & 81.33 & 71.66 & 82.00 & 81.00 & 90.00 & 5.25 & 0.12 & 0.33 & 0.20 \\
\hline \multicolumn{14}{|c|}{ Villi height/crypt ratio } \\
\hline Duodenum & $12.58^{\mathrm{bc}}$ & $13.00^{\mathrm{abc}}$ & $14.01^{\mathrm{ab}}$ & $12.28^{b c}$ & $12.10^{c}$ & $14.67^{\mathrm{a}}$ & $13.01^{\mathrm{abc}}$ & $14.07^{\mathrm{ab}}$ & $13.51^{\mathrm{abc}}$ & 0.37 & 0.27 & 0.0005 & 0.011 \\
\hline Jejunum & $9.80^{c}$ & $10.25^{\mathrm{abc}}$ & $11.09^{\mathrm{abc}}$ & $9.97^{b c}$ & $9.96^{b c}$ & $12.03^{\mathrm{a}}$ & $9.97^{b c}$ & $11.80^{\mathrm{ab}}$ & $10.18^{\mathrm{bc}}$ & 0.37 & 0.59 & 0.003 & 0.002 \\
\hline lleum & 9.11 & 10.06 & 10.45 & 9.71 & 11.42 & 12.17 & 10.76 & 10.94 & 9.87 & 0.72 & 0.14 & 0.20 & 0.27 \\
\hline \multicolumn{14}{|c|}{ Goblet cell number $\left(\mathrm{mm}^{2}\right)$} \\
\hline Duodenum & $881.30^{\text {de }}$ & $1,006.6^{\mathrm{bc}}$ & $1,053.30^{\mathrm{abc}}$ & $1,006.00^{c}$ & $1,086.30^{\mathrm{ab}}$ & $1,120.00^{\mathrm{a}}$ & $805.33^{\mathrm{e}}$ & $1,120^{\mathrm{a}}$ & $978.00^{\text {cd }}$ & 20.46 & 0.0001 & 0.0001 & 0.30 \\
\hline Jejunum & $1,248.60^{\mathrm{a}}$ & $1,236.3^{\mathrm{a}}$ & $1,273.00^{\mathrm{a}}$ & $1,212.50^{\mathrm{ab}}$ & $1,060.30^{b}$ & $1,171.30^{\mathrm{ab}}$ & $1,204.30^{\mathrm{ab}}$ & $1,230.30^{\mathrm{ab}}$ & $1,230.60^{\mathrm{ab}}$ & 33.05 & 0.001 & 0.26 & 0.09 \\
\hline Ileum & $1,430.00^{\mathrm{a}}$ & $1,410.3^{\mathrm{ab}}$ & $1,409.30^{\mathrm{ab}}$ & $1,298.00^{\mathrm{bc}}$ & $1,286.70^{c}$ & $1,317.30^{\mathrm{abc}}$ & $1,326.70^{\mathrm{abc}}$ & $1,314.30^{\mathrm{abc}}$ & $1,392.0^{\mathrm{abc}}$ & 24.6 & 0.0002 & 0.23 & 0.48 \\
\hline
\end{tabular}

SEM, standard error of the mean.

a,b Means in each row with no common superscript differ significantly $(p \leq 0.05)$. 
Gln, caused a longer duodenum and jejunum VH and higher BWG. Nassiri Moghaddam and Alizadeh Ghamsari [21] observed that $1.0 \%$ and $1.5 \%$ dietary Gln supplementation increased the duodenum and jejunum $\mathrm{VH}, \mathrm{VW}$, and villus surface area of broiler chickens at days 21 and 42 of age. It has been well documented that maximum development of the small intestine occurs at 10 first day of age [22], therefore adequate feeding in the first days has an important role in broiler chicken performance [10]. Gln is an important substrate or energy source for maturation of fast proliferating cells such as enterocytes and hence its supplementation in the first days of age may have activated the cell mitosis and caused the higher $\mathrm{VH}$. It has been stated that the longer $\mathrm{VH}$ and villous surface area positively related to BWG and growth performance $[23$, 24]. Hence the better performance of $0.5 \%$ Gln fed birds in current experiment is due to the higher villus length. The large surface area by higher VH results in better fed utilization [11] and consequently higher nutrient absorption that reflected in higher BWG and feed efficiency.

The Gln fed birds had the deeper CD in current study. Our results are inconsistent with those of Murakami et al [10] and Soltan [9] who reported that CD was shorter with Gln consumption. However, Xaio et al [4] stated that 1.0\% Gln significantly increased the $\mathrm{VH}, \mathrm{VW}$, villus surface area, and VD. The higher $\mathrm{CD}$ of Gln consuming birds in our experiment may be associated with increased $\mathrm{VH}$ [4].

In a consistent with performance and intestine morphology, ascites mortality was affected by dietary Gln and the Gln fed birds had the lowest mortality. Nascimento et al [25] indicated that increasing the glutamine consumption $(0,5,10,15$, and $20 \mathrm{~g} / \mathrm{kg}$ ) linearly reduced the coccidiosis incidence from days 1 to 21 of age. Consistently, Fathi et al [26] indicated a decreased total ascites mortality ( $38 \%$ vs $25 \%$ ) with the consumption of $100 \mathrm{~g} / \mathrm{kg} \mathrm{Gln}$. Similarly, the reduction of ascites incidence in Gln fed birds in the current study might be associated with improved $\mathrm{O}_{2}$ utilization of gut. Moreover, Gln supplementation might have improved the intestinal lumen health, increased the intestinal integrity against pathogens, improved immune responses with secretion of IgA and had protective effects on jejunum against oxidative stress as indicated by morphological traits $[4,11]$. It has been estimated that almost $20 \%$ of the total energy expenditure by animal is related to intestinal epithelium maintenance [27]. Therefore, the body net energy and oxygen avialability may be enhanced while epithelial turnover or intestinal lumen damage decreased. These results suggest that $\mathrm{Gln}$ may reduce $\mathrm{O} 2$ utilization by gut and allowing birds to use more oxygen and maintain their current high metabolism in cold temperature. In supporting this discussion, Santose et al [5] reported reduced ascites incidence in prebiotic treated birds under hypoxic condition (high altitude) and suggested that prebiotic treatment may revoke the effect of hypoxia in broilers along with stimulation of intestinal devel- opment and availability of more oxygen for body metabolism.

Although Arg supplementation did not affect the performance and ascites mortality in the current experiment but ileal VW, duodenum, and jejunum VH/CD ratio was increased and jejunum CD decreased by dietary Arg addition. Saki et al [28] reported no significant effect of $1.5 \mathrm{~g} / \mathrm{kg}$ Arg on performance of broilers in hypobaric condition. Moreover, Khajali et al [8] indicated that dietary consumption of $10 \mathrm{~g} / \mathrm{kg}$ Arg did not change the broiler performance at hypoxic condition (high altitude). In agreement with current results, Murakami et al [15], showed that dietary $\operatorname{Arg}(10 \%, 20 \%, 30 \%$, and $40 \%$ higher than NRC recommendation) during starter period, improved the intestine mucosa development and even production performance. Xaio et al [4] indicated that $1 \%$ Arg supplementation exhibited significantly higher ratio of $\mathrm{VH}$ to $\mathrm{CD}$ and total antioxidant capacity activity and better morphological structure of rat jejunum under oxidative stress. Arg involvement in polyamines (putrescine, spermine and spermidine) synthesis which is known as biogenic amines plays an important role in development of small intestine, colonic mucosa, cell division and tissue growth [17]. Khajali et al [8] reported that dietary Arg supplementation $(10 \mathrm{~g} / \mathrm{kg})$ increased blood NO, duodenum and jejunum $\mathrm{VH}$, VW and surface area, and decreased RV/TV ratio and consequently reduced PHS in broiler under hypoxia condition. Higher $\mathrm{VH}$ and $\mathrm{VH} / \mathrm{CD}$ ratio may be related with polyamines production and activation of cell mitosis or NO by additional levels of Arg supplementation which enhanced the gut development and nutrient absorption in small intestine.

In current experiment, both the Gln and Arg caused the greater GCN of the intestine especially duodenum. Goblet cells synthesize and secrete mucin and play crucial role in integrity and protection of epithelium [29]. Mucus generated by GCN is the first defense line against intestinal pathogens [29]. Duodenum is the first segment in small intestine with the faster cell renewal which receives the physical and chemical substrate after stomach. Although the main reason for the higher GCN in duodenum by Gln And Arg is not known yet, stimulation of this segment by supplementation of both the amino acids possibly caused the higher mucus secretion or an increase in goblet cell turnover.

No information is available regarding the intestinal GCN under ascites condition especially in amino acids supplemented diets. In a stressful condition under Salmonella Typhimurium challenge, higher goblet cell density and lower villus surface area have been observed in broilers [30]. Gln is an important anti stress amino acid [12] that nourishes the intestinal enterocytes and immune cells [13]. The lower GNC in jejunum and ileum of Gln fed birds in current experiment can be related to the beneficial effects of this amino acid on immunity regulation of small intestine segments which may be provided specific condition in intestinal lumen and have decreased the 
mucin secretion.

Although many beneficial effects of Gln (0.5\%) and Arg (130\%) supplementation alone or together were observed for many parameters (performance, intestine morphology, and ascites mortality) in current experiment, these results were not supported by an additional level of Gln (1\%) or Arg (160\%). This phenomenon may be related to the possible negative effects of higher levels of Gln and Arg on broilers. It has been shown that the $1.5 \%$ and $2 \% \operatorname{Gln}[9]$ or $4 \% \operatorname{Gln}[11]$ had toxic effects and resulted in body weight depression in broilers. Gln acts as a precursor for ammonia synthesis in the gut and kidney and is a nitrogen shuttle which protects the body from high levels of ammonia [31]. In birds, ammonia is excreted in urine in the form of uric acid and Gln is involved in uric acid synthesis [32]. A possible explanation for the lower ascites mortality of $0.5 \% \mathrm{Gln}+130 \%$ Arg fed birds than other combinations of Gln and Arg, may be related to the lower excreted nitrogen which may hypothetically cause the reduced oxygen need for extra nitrogen metabolism.

\section{CONCLUSION}

According to the results of the current experiment, the supplementation of diet with $0.5 \%$ Gln alone or in combination with Arg supplementation at $130 \%$ of Ross recommendation increased the villus length and decreased the muscular layer of intestine, improved the performance and consequently decreased the ascites mortality in broiler chickens with cold induced ascites. Higher levels of Gln (1.0\%) and Arg (160\%) alone or in combination, does not positively affect the ascites mortality.

\section{CONFLICT OF INTEREST}

We certify that there is no conflict of interest with any financial organization regarding the material discussed in the manuscript.

\section{ACKNOWLEDGMENTS}

The work was supported by the Zanjan and Urmia Universities.

\section{REFERENCES}

1. Balog JM. Ascites syndrome (pulmonary hypertension syndrome) in broiler chickens: are we seeing the light at the end of the tunnel? Avian Poult Biol Rev 2003;14:99-126.

2. Luger D, Shinder D, Rzepakovsky V, Rusal M, Yahav S. Association between weight gain, blood parameters, and thyroid hormones and the development of ascites syndrome in broiler chickens. Poult Sci 2001;80:965-71.

3. Yen JT, Nienaber JA, Hill DA, Pond WG. Oxygen consumption by portal vein-drained organs and by whole animal in conscious growing swine. Proc Soc Exp Biol Med 1989;190:393-8.

4. Xiao L, Cao W, Liu G, et al. Arginine, N-carbamylglutamate, and glutamine exert protective effects against oxidative stress in rat intestine, Anim Nutr 2016;2:242-8.

5. Santos FS, Farnell MB, Te'llez G, et al. Effect of prebiotic on gut development and ascites incidence of broilers reared in a hypoxic environment. Poult Sci 2005;84:1092-100.

6. Laudadio V, Passantino L, Perillo A, et al. Productive performance and histological features of intestinal mucosa of broiler chickens fed different dietary protein levels. Poult Sci 2012;91: 265-70.

7. Jazideh F, Farhoomand P, Daneshyar M, Najafi G. The effects of dietary glutamine supplementation on growth performance and intestinal morphology of broiler chickens reared under hot conditions. Turkey J Vet Anim Sci 2014;38:264-70.

8. Khajali F, Heydary Moghaddam M, Hassanpour H. An LArginine supplement improves broiler hypertensive response and gut function in broiler chickens reared at high altitude. Int J Biometeorol 2014;58: 1175-9.

9. Soltan MA. Influence of dietary glutamine supplementation on growth performance, small intestinal morphology, immune response and some blood parameters of broiler chickens. Int J Poult Sci 2009;8: 60-8.

10. Murakami AE, Sakamoto MI, Natali MRM, Souza LMG, Franco JRG. Supplementation of glutamine and vitamin e on the morphometry of the intestinal mucosa in broiler chickens. Poult Sci 2007;86:488-95.

11. Bartell SM, Batal AB. The effect of supplemental glutamine on growth performance, development of the gastrointestinal tract, and humoral immune response of broilers. Poult Sci 2007;86: 1940-7.

12. Newsholme P. Why is l-glutamine metabolism important to cells of the immune system in health, post injury, surgery or infection? J Nutr 2001;131:2515-22.

13. Wu G, Bazer FW, Johnson GA, et al. Important roles for l-glutamine in swine nutrition and production. J Anim Sci 2011; 89:2017-30.

14. Domeneghini C, Di Giancamillo A, Savoini G, et al. Structural patterns of swine ileal mucosa following l-glutamine and nucleotides administration during the weaning period. An histochemical and histometrical study. Histol Histopathol 2004; 19:49-58.

15. Murakami AE, Fernandes JIM, Hernandes L, Santos TC. Effects of starter diet supplementation with arginine on broiler production performance and on small intestine morphometry. Pesq Vet Bras 2012;32:259-66.

16. Newsholme P, Brennnan L, Rubi B, Maechler P. New insights into amino acid metabolism, beta-cell function and diabetes. Clin Sci 2005; 108:185-94.

17.Loser C, Eisel A, Harms D, Foelsch UR. Dietary polyamines are essential luminal growth factors for small intestinal and 
colonic mucosal growth and development. Gut 1999;44:12-6.

18. Druyan S, Shlosberg A, Cahaner A. Evaluation of growth rate, body weight, heart rate, and blood parameters as potential indicators for selection against susceptibility to the ascites syndrome in young broilers. Poult Sci 2007;86:621-9.

19.Daneshyar M, Kermanshahi H, Golian A. Changes of biochemical parameters and enzyme activities in broiler chickens with cold-induced ascites. Poult Sci 2009;88:106-10.

20. Mohammadagheri N, Najafi R, Najafi GR. Effect of dietary supplementation of organic acids and phytase on performance and intestinal histomorphology of broilers. Vet Res Forum 2016;7:189-95.

21.Nassiri Moghaddam H, Alizadeh-Ghamsari AH. Improved performance and small intestinal development of broiler chickens by dietary L-glutamine supplementation. J Appl Anim Res 2013;41:1-7.

22. Noy Y, Sklan D. Metabolic responses to early nutrition. J Appl Poult Res 1998;7:437-51.

23. Kelly D, Smith JA, McCracken KJ. Digestive development of the early-weaned pig. 1. Effect of continuous nutrient supply on the development of the digestive tract and on changes in digestive enzyme activity uring the first week post-weaning. Br J Nutr 2001;65:169-80.

24. Nkukwana TT, Muchenje V, Masika PJ, Mushonga B. Intestinal morphology, digestive organ size and digesta $\mathrm{pH}$ of broiler chickens fed diets supplemented with or without Moringa oleifera leaf meal. S Afr J Anim Sci 2015;45:362-70.
25. Nascimento GM, Leandro NSM, Café MB, et al. Performance and intestinal characteristics of broiler chicken fed diet with glutamine in the diet without anticoccidials agents. Rev Bras Saúde Prod Anim 2014;15:637-48.

26. Fathi M, Tanha T, Daneshyar M. Effects of glutamine supplementation on growth performance, antioxidant status in broilers with pulmonary hypertension syndrome. Iran J Appl Anim Sci 2014;4:579-85.

27. Mcbride BW, Kelly JM. Energy cost of absorption and metabolism in the ruminant gastrointestinal tract and liver: a review. J Anim Sci 1990; 68:2997-3010.

28.Saki AA, Haghighat M, Khajali F. Supplemental arginine administered in ovo or in the feed reduces the susceptibility of broilers to pulmonary hypertension syndrome. Br Poult Sci 2013;54:575-80.

29. Montagne L, Piel C, Lalles JP. Effect of diet on mucin kinetics and composition: Nutrition and health implications. Nutr Rev 62:105-14.

30. Fasina YO, Bowers JB, Hess JB, Mckee SR. Effect of dietary glutamine supplementation on Salmonella colonization in the ceca of young broiler chicks. Poult Sci 2010;89:1042-8.

31. Tapiero H, Mathe G, Couvreur P, Tew KD. Free amino acids in human health and pathologies -II. Glutamine and glutamate. Biomed Pharmacother 2002;56:446-57.

32. McDonald P, Edwards PA, Greenhalgh JFD, Morgan CA. Metabolism. In: Animal nutrition. 6th ed. Pearson Education Limited; 2002. pp. 220-1. 